\title{
Critical Discourse Analysis of Hassan Sheheryar's Interviews: Pakistani Fashion Designer
}

Zainab Shafaat* and Hina Javaid

Department of Home Economics, Textiles and Clothing, Lahore Garrison University, Lahore, Pakistan

\begin{abstract}
This paper intends to analyse the interviews of one of the most prominent Pakistani fashion designer Hassan Sheheryar Yasin, known as HSY. The study aims at plunging deep into the ideologies, values and societal trends set by the leading personas through the language they select to empower and market themselves as brand. Latent Themes and meaning with reference to individual, power and society will be analysed and discussed thoroughly. As Pakistani fashion industry is a blooming avenue it is beneficial to understand the important underlying motives. The palpable themes stemming from the critical analysis of the discourse were timelessness, classic and Elegant Fashion fusion endeavour, believing on fate, modern women perspective, self-appraisal, self-reliance and satisfaction, success and achievements, strong business, conservation of culture and concern for community. Seven interview scripts were taken from online fashion magazines websites. The six scripts from online resources were studied in-depth qualitatively by using critical discourse analysis technique based upon Norman Fairclough's assumptions. HSY emerged as strong cosmopolitan exercising great insight based driving force to bind conservative fashion ideologies and modern needs together.
\end{abstract}

Keywords: Fashion designer; Discourse analysis; Self-appraisal; Strong business; Conservation of culture

\section{Introduction}

Pakistani fashion industry has gained a strategic importance over time. Many strong fashion houses have evolved. Pakistani Fashion Industry has been recognised throughout the world due to its versatile designers, models, and fashion shows [1]. The evolution of conventional merchandizing to the couture designing, the fashion schools has eased in expediting the boom in the fashion cult. Now, Pakistani fashion designers have emerged as international fashion personas and trend setters and arose as global competitors.

The language of media and media fronts has great powerful influence over the ideologies and beliefs of the followers as well as the social trends. Hatim and Mason cited in this paper analysis the role of constructed ideologies in the Language of the fashion designers.

Hassan Sheheryar Yasin, known as HSY, is a Pakistani fashion designer whose fashion collections are admired in the international market. He was a much prised student of Pakistan School of Fashion Design class of 2000. Yasin has been reported in one hundred most influential people in Pakistan in a book by Jalandhari [2]. He is in connection with the La Chambre Syndicale De La Couture Parisienne in France at present. HSY have an honours degree in couture and is currently on the board of directors and the executive committee of the fashion institute. Hassan Shehryar had hosted a prime-time talk show "Tonite" with HSY on a TV channel Hum Sitaray.

Starting in 1994 as a fashion choreographer, HSY worked both as a choreographer and designer in various shows within Pakistan and international shows including Dubai, London, New York City and Toronto. Yasin's own Fashion label was introduced in the year 2000. Starting as a bridal and formal wear couture house, it became one of Pakistan's most recognized fashion labels and employs over three fifty people and six stores internationally (including Dubai), with the flagship housed in Lahore. In 2003, Karachi-based Diva Magazine placed Yasin on the cover of their "Most Powerful People" issue and as one of their 10 "Faces of the Year". Yasin introduced a jewellery line under the HSY in 2007. Having spent the early part of his life in New
York, Lahore and Karachi, Sheru's creations have retained the indelible mark of fusion peppered with Eastern sensibilities [3]. He also runs an event management company and is the Pakistani brand ambassador for international brands like Porsche, Ponds and Toy Watch. HSY has an unflinching drive towards success.

The analysis is based on Norman Fairclough's assumptions in critical discourse analysis, stating that "ideologies reside in texts" that "it is not possible to 'read off' ideologies from texts" and that "texts are open to diverse interpretations" [4].

\section{Objective of the study}

The research intends to highlight the use of language for the sake of gaining power and stature in the Society and specifically in the Fashion world of Pakistan.

\section{Significance of the research}

The significance of the study resides in the augmentation of understanding of societal patterns of Pakistani fashion world through the linguistic manifestation as radiated by the governing agents of the field. HSY, a well-known designer, is a part of numerous national and international fashion forums and has emerged as a consistent successful manipulator of the value configuration of Fashion horizon because he acclaimed a variety of followers around the world. The findings may promote the prevailing trends as set by him and also serve as catalyst for the upcoming twists. Overall, the language as used by HSY tends to influence the values, ideologies and roles in the society.

*Corresponding author: Zainaab Shafaat, Lecturer, Department of Home Economics, Textiles and Clothing, Lahore Garrison University, Lahore, Pakistan, Tel+92-3315290750; E-mail: zainab.shafaat1@gmail.com

Received May 10, 2018; Accepted May 17, 2018; Published May 24, 2018

Citation: Shafaat Z, Javaid H (2018) Critical Discourse Analysis of Hassan Sheheryar's Interviews: Pakistani Fashion Designer. Arts Social Sci J 9: 367. doi: 10.4172/2151-6200.1000367

Copyright: $\odot 2018$ Shafaat Z, et al. This is an open-access article distributed under the terms of the Creative Commons Attribution License, which permits unrestricted use, distribution, and reproduction in any medium, provided the original author and source are credited. 


\section{Rationale of the study}

Hassan Shehryar Yasin is Pakistani fashion industries most celebrated and famous versatile designer, an insight into his view point would provide us with his hidden aims, values and motives regarding his fashion business. It will also shed light on the societal concerns of our Pakistani designers particularly Hassan Shehryar. This effort of analysing the interviews of HSY will reveals the motivating factors and goals for which he is expanding his business.

\section{Methods}

The methodology employed for analysing interviews was critical discourse analysis. This technique provides us with an opportunity to discover the hidden themes and meanings in text and talk, and reveal the conscious and unconscious societal problems. According to Batstone, who claims that "critical discourse analysis seeks to reveal how texts are constructed so that particular (and potentially indoctrinating) perspectives can be expressed delicately and covertly; because they are covert, they are elusive of direct challenge, facilitating what Kress calls the 'retreat into mystification and impersonality" [5]. Critical Discourse Analysis started in the late 1980s, it has become well-known as an approach for the analysis of text and discourse that is unified. This approach is known for not only describing but also explaining and critically assessing the critical role of text and talk in creating, maintaining, and legitimating inequality, oppression, and injustice in society [6].

Critical Discourse Analysis is generally a shared perspective on doing linguistics, semiotic or discourse rather than being homogenous model or a school or a paradigm [7].

The main objective is to perceive language use as social practice. The speakers of language use it along with a set of cultural, psychological and social frameworks. Critical discourse analysis accepts this social context and studies the connections between textual structures and takes this social context into account and explores the links between textual structures and their function in interaction within the society. It should be eminent that the relationship is bi-directional. Not only the language use is affected by its grounded-ness within certain frame of cultural or social practice, but also the use of language guides and shapes the social and cultural context it finds itself in. The one element of Critical discourse analysis by which it is distinguished from other forms of discourse analysis lies in its characteristic of 'critical'. 'Critical' implies showing connections and causes which are hidden; it also implies intervention, for example providing resources for those who may be disadvantaged through change" [8]. It is necessary to expose the deep meanings, since they are not visible to the involved individuals, owing to this reason they cannot be fought against.

The interview of Hassan Shehryar were taken from 6 different websites and a critical discourse analysis was conducted to analyse the apparent and connotative meaning within the discourse.

\section{Analysis and Discussion}

Major themes that emerged from the interviews were self-Appraisal and satisfaction, success, concern about culture, timeless, classic, and elegant fashion, modern Women, skills of designer, believe on fate, no spare time, and social and community service. The themes are discussed below along with verbatim from the interview experts.

\section{Self-appraisal and satisfaction}

In his interviews HSY expresses a desire to be something very special and out of this world. Struggle and success is the ideology of statements. He seems to thinks about himself as a passionate and obsessive individual, especially about his work. He appraises and acknowledges his own abilities on several occasions and in various ways. Talking about self-confidence, personality, love for fashion, love for creativity, and competitive person etc. He mostly talks about himself in acknowledging perspective and perhaps giving credit to his qualities for success. He said in one of his interview:

"I wanted to be able to live and do what I was passionate about. I wanted to do more than just be a model. I wasn't going to sit and do a desk job. Fashion is something I always wanted to do. I like to see women in beautiful clothes. What better way to do it than do it yourself? I have always loved fashion and that's something I wanted to do since the age of five! I have always had an obsession with dress designing".

According to Galinsky clothes have a cognitive effect on the wearer and the perceiver as well. This cognitive effect results from a symbolic meaning attached to the clothing along with real wearing of clothing. This phenomenon of controlling the symbolic meaning by designing dresses for the customers over their mind is satisfying for the designer. This aspiration make him a successful fashion designer who wants to be surrounded by beautiful women. In another interview he says that traveling inspires him and give him ideas for work. He gets his inspiration from small things, colors and hues of the monsoon season.

"I love work, I enjoy it... I don't even see it as working. Only two things I live for... work and travel. I have an obsession for seeing the world. I want to see every city in the world, from crazy places like some small little city in China to Kenya and Nairobi, which I haven't been to, but I'm dying to. I don't care, I want to see everything. I work, and then I run away, and I come back with all these ideas and I work some more".

Another revealed theme is great obsession with his work. The sense of achievement coupled with works of personal interests leads to such involvement. He expresses his love for traveling. Being a fashion designer traveling is very important. As it a good way to understand the local culture, traditions and demand of people, making it easier to market the product according to the societal expectations of the local people. The desire to travel and see the world also signifies for the understanding of the world as a whole.

\section{Success and achievements}

Hassan is an achievement oriented person, he has a strong desire to excel as he dearly prises his achievements which is clearly evident in his interviews.

"During that time I decided not to throw away my career and become someone conventional. The government of Pakistan has just appointed me in the Board of Directors of the school as well and in the Executive Committee. HSY is the winner of Lux style Fashion designer of the year award 2005-6".

"Eye of the storm" this is the remark that HSY wants his brand to be among his competitors. The competition and desire to be above all others is evident in the phrase. Among the hurricane and sensationalism of fashion, Hassan Sheheryar Khan wants his brand to be the focus point "eye of storm" in fashion industry.

"I believe every single designer has a different role when viewing fashion. At HSY we always feel that if fashion portrays a slot of crazy hurricane competed with the sensationalism of fashion trends then we want HSY to be the eye of the storm. I'm proud to claim that our pret wear now competes with most brands in the market in terms of price but 
have that same signature style and elegance. I design for men and women of different age groups".

He has a very successful business and the traveling toward establishing a flourishing business is evident in the expression. The year 2000 was the turning point for his business as he started his own brand.

"Eleven Years and 206 Fashion Shows. In 1994, when I was doing my A-levels, I got really serious about it and decided to go for it. I started directing fashion shows. When I graduated from the Pakistan School of Fashion Design, I worked for a couple of designers for a few months, but I wanted to do my own thing so I started my label at the end of 2000. We started in 2000 with one employee and now we have over 300 people working for us and we have stores in Lahore, Karachi, studios in Dubai and London".

\section{Strong Business}

Yasin expresses a strong desire for expanding his well-established business and launching new business line also incorporating online sales. To cater the foreign customers and providing their orders is again a different aspect of selling overall contributing to his business. Future plans and expansion projects are mentioned in his interview.

"My clients from as far as the US, Norway and France can now place their orders online, completely hassle-free. E-commerce has become an essential part of every business these days and made our lives as a brand much easier. There are a lot more projects in the pipeline, some collaborations and some expansion of retail networks, etc. We will update all our fans as things develop".

In another place he say about his Middle East cliental:

"We have a strong clientele in the Middle East. I'm proud to claim that our pret wear now competes with most brands in the market in terms of price but have that same signature HSY style and elegance. I design for men and women of different age groups. Basically, a retail business will run anywhere in the world but just now it is difficult, economically, because the whole world is going through so many changes".

\section{Conservation of Culture}

The designer talks about eastern culture and an ardent desire for its conservation. He expresses his love for eastern culture and traditions. Clothing is one of the visible cues that reflect believes, customs, traditions and history of a society. Through attire, people exhibits their social and cultural identities [9]. Edensor also suggests that clothing is a marker cultural identity and is worn in national ceremonies or cultural activities to express identity [10]. Attire is one of the material cultural artefacts. This artefact could be manipulated unintentionally or intentionally ensuring their alliance with the particular ethnic group or nation's values and beliefs. The symbolic nature of cloths incorporate styles, brands, retailer outlets, uniforms, and also membership to certain subcultures. The meanings can contribute to an individual's sense of who they actually are. Fashion shapes both our self-concepts and our internal feelings [11]. In an interview he says that:

"At heart I'm a big eastern boy. I like our eastern sense of things. Our culture is so rich, it's thousands of years old. It excites me very much to be a part of that and to be able to transcend it to New York. So many cultures are losing their identity, we need to keep ours" [12].

\section{Modern Women}

In his interviews he mentions "modern women". He presents a concept of an independent, strong and modern women. This concept of modern women is that of a working women. HSY says that:

"I design for the woman of today and that's a strong, modern, independent woman; not someone who would stay home all the time. A working woman who works hard and needs clothes that not only look like a million bucks but feel like a million bucks too".

His design philosophy is to amalgamate the contemporary female silhouettes with traditional rich eastern techniques of dress making. $\mathrm{He}$ also classifies eastern women as mysterious and enigmatic. Expressing his thoughts about:

"It's about the mystery of an eastern woman. She doesn't necessarily need to show everything she has in the first five seconds. The design philosophy at HSY to combine contemporary silhouettes with traditional techniques of old, making it appealing to an international clientele who have an appreciation for the grandeur and extravagance of a regal past but expect further innovation and creativity".

Appreciating the eastern women, he focuses his design concept on the eastern women's silhouette. His fashion creations revolve around the traditional bridal dresses, embellished with generous embroidery, involving a large variety of patterns.

"The inspiration behind the collection is the spiritual beauty of the East, celebrating our affluent time honoured heritage with an emphasis on the use of cuts, both ageless and contemporary, to craft a look that is elegantly classic".

\section{Timeless, Classic, and Elegant Fashion}

HSY labels his fashion collection classic which could be worn regardless of the time. Although fashion is a style of consumer product or behaviour that is adopted by a, discernible proportion of members of a social group at a particular time because that is perceived to be socially appropriate for the time and situation [13]. HSY being a fashion designer considers himself above this concept of changing fashion. In his interviews he says that:

"It's the centre of timeless classic couture you can wear now and maybe you can take out 20 years later and it will still be relevant. We don't believe in trends-of-fashion; we want it to be something timeless, classic and elegant".

"HSY is about a lifestyle and not just about clothes, and that's what we want to sell - a timeless, classic lifestyle that will fit well with today's fast paced modern life - we are not off the rack designers".

\section{Believe on fate}

Comments within his discourse reveals his believe in destiny, he says that his entrance into the fashion industry was easy owing to the reason that he has already been into it as a model and choreographer. Fate is a concept related to religion. This theme signifies his core concept.

"Yes, I strongly believe in fate. I was very lucky because I had already built a name in the industry and media as a successful choreographer, so that initial media push was easy".

\section{Concern for community}

In his interviews he expresses his concern for society and a desire to give back his community. Devoted with his work, he views his work a prised part of his life. His concern for contribution in the society and community. Fashion-oriented designs have both positive and negative 
effects. One of the plus point of fashion is that it promotes vitality, creativity and uniqueness in design [14]. Yasin says in his interview that: "For me every collection is unique in its own right. This year my collections/campaigns have been more focused on giving something back to the community and hence there is a social angle that has been prominent in my work in 2014" (Figure 1 and Table 1).

\section{Analysis of frequently used words and phrases}

The excessive use of word "want" to ( 15 times) and "to be able to" shows the desire to achieve higher standards in his business. Concerns about the "world" is an expression of his desire to bring change in the world. Word count shows a stress on the word modern and fashion, the core idea of modern, brings fashion into existence as fashion is due to ever changing world scenario. As Hassan Shahryar has worked exclusively on women fashion collection, he imagines women in a more powerful, magnetic, charismatic and modern role as he frequently expresses that he design clothing for modern women (Tables 1-3).

Self-importance and high self-esteem can also be observed through the utterance of full name (11 times) by HSY himself in his interviews as if using a second person narration. Being a leading and prominent figure, he seems to be aware of the endorsed persona he has become and presents himself as a remote brand. Psychologically, it indicate presence of a tinge of narcissism, which is a "vulnerable aspects like fluctuating self-esteem and emotional conflicts" but here we can take it as self-love and faith in one self's strong personality with practice of selfreliance because it is the common practice in Fashion world to market the name and HSY never flaunted and swayed his low emotional side $[15,16]$. Rather, he has appeared as conscious emotionally intelligent figure that is well aware of brandishes (Tables 1-3).

\section{Conclusion}

The themes show that Hassan stresses on a deep struggle for success that he took for making his business in his interviews. He also shows concern for cultural heritage and its conservation and progression by promoting Pakistani culture in the international market $[17,18]$. He

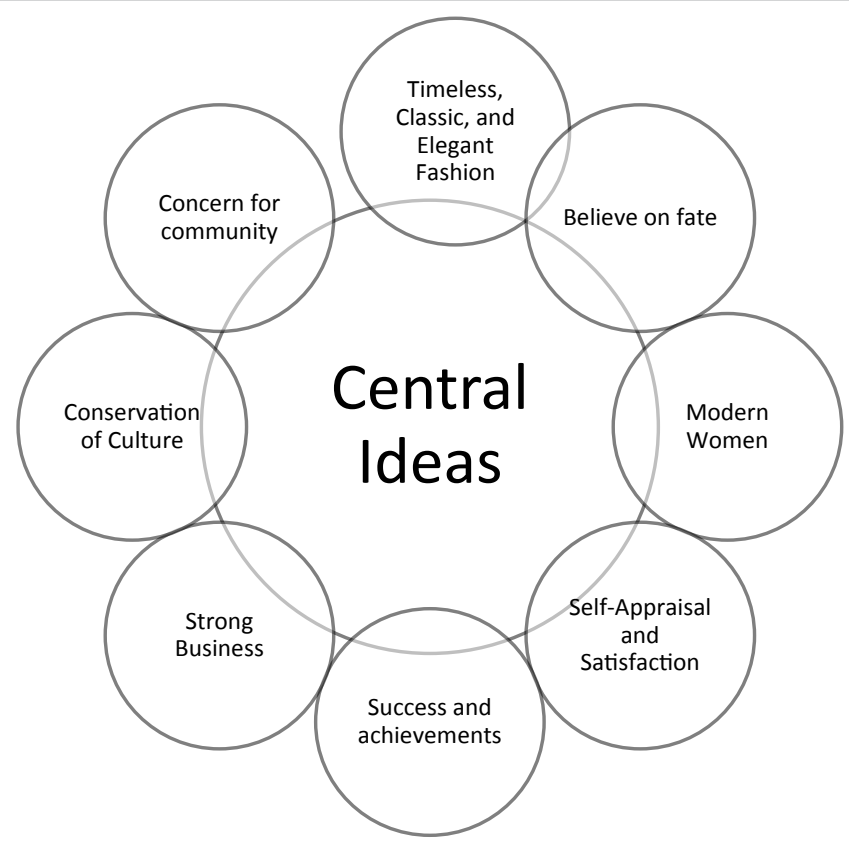

Figure 1: Central Ideas.

\begin{tabular}{|c|c|}
\hline \multicolumn{2}{|c|}{ Word count analysis of single words } \\
\hline Word & Frequency \\
\hline Fashion & 17 \\
\hline Want & 15 \\
\hline Work & 13 \\
\hline Design & 11 \\
\hline Hassan Sheheryar Khan & 11 \\
\hline Cloth & 10 \\
\hline Woman & 9 \\
\hline World & 9 \\
\hline Show & 8 \\
\hline Rich & 7 \\
\hline Women & 7 \\
\hline Modern & 7 \\
\hline
\end{tabular}

Table 1: Word count analysis of single words.

\begin{tabular}{|c|c|}
\hline \multicolumn{2}{|c|}{ Word count of two words phrases } \\
\hline 2 word phrases & Occurrences \\
\hline The world & 8 \\
\hline To do & 7 \\
\hline Wanted to & 7 \\
\hline Want to & 6 \\
\hline I wanted & 6 \\
\hline The modern & 5 \\
\hline
\end{tabular}

Table 2: Word count of two phrases

\begin{tabular}{|c|c|}
\hline \multicolumn{2}{|c|}{ Word count of three word phrases } \\
\hline 3 word phrases & Occurrences \\
\hline I wanted to & 6 \\
\hline Wanted to do & 4 \\
\hline Be able to & 4 \\
\hline In the world & 4 \\
\hline
\end{tabular}

Table 3: Word count of three word phrases.

also talks about the role, modern women can perform for the sake of Pakistan and he claims that his fashion collection is primarily for today's modern independent women. The women he talks about are independent, modern and working; who has style and elegance. $\mathrm{He}$ presents the image of a dynamic women and stresses this by adding such elements in his fashion. He expresses about his obsession and love for travelling. Which is also evident in his style. Believe in the role of fate in success depicts his believe in the divine power.

\section{Future Recommendations}

Detailed analysis should be conducted regarding the values and goals of other prominent fashion designers. It would be advisable to conduct case studies of the fashion designers which would not only shed light on the motives of fashion designers but also give us a holistic idea about evolution of our local fashion system. Pakistan has a promising textile and fashion industry therefor societal aspects should be studied rigorously.

\section{References}

1. Khan SA, Ramzan N, Shoaib M, Mohyuddin A (2015) Impact of word of mouth on consumer purchase intention. Sci Int 27: 479-482.

2. Jalandhari MA (2014) 100 Pakistani the famous and influential, Pakistan, Universal Oxford Publication.

3. Qamar S (2015) Broadening the Hassan sheheryar khan Family. The express tribune.

4. Fairclough N (1995) Critical Discourse Analysis London, Longman. 
Citation: Shafaat Z, Javaid H (2018) Critical Discourse Analysis of Hassan Sheheryar's Interviews: Pakistani Fashion Designer. Arts Social Sci J 9: 367. doi: 10.4172/2151-6200.1000367

Page 5 of 5

5. Batstone R (1995) Grammar in Discourse Attitude and Deniability. In: Cook G Seidlhofer B (eds.) Principle \& Practice in Applied Linguistics, Oxford University Press, pp: 197-213.

6. Leeuwen TV (2015) Critical Discourse Analysis The International Encyclopaedia of Language and Social Interaction, pp: 1-7.

7. Van Dijk TA (1996) Discourse Power and Access. In: Caldas-Coulthard CR, Coulthard M (eds.) Texts and Practices Readings in Critical Discourse Analysis, Routledge, London, pp: 84-106.

8. Fairclough N (1992) Discourse and Social Change London, Polity Press.

9. Kuma-Kpobee M, Power J, Otieno R (2008) Utilisation of Traditional Dress The Case of Slit and Kaba in Ghana, Textile Institute 86th World Conference, Conference Proceedings Hong Kong.

10. Edensor T (2002) National Identity Popular Culture and Everyday Life, Oxford, Berg.

11. Tombs A (2010) Do our feelings leak through the clothes we wear? Australian \&
New Zealand Marking Academy Conference, Australia: Queensland University of Technology.

12. Interview of Hassan Shehriyar Yasin.

13. Sproles GB, Burns LS (1994) Changing appearance: understanding dress in contemporary society. Fairchild Publication, New York.

14. Walker S (2006) Sustainable by design: Explorations in theory and practice. Routledge, London.

15. Jauk E, Benedek M, Koschutnig K, Kedia G, Neubauer AC (2017) Self-viewing is associated with negative affect rather than reward in highly narcissistic men: an fMRI study Scientific Reports 7: 5804.

16. Khalid S (2014) Hassan sheheryar khan couture king of Pakistan Mag the weekly interview.

17. Galinsky A (2012) Enclothed Cognition. Journal of Experimental Socia Psychology 48: 918-925.

18. Safdar A (2008) For Pakistan will make its mark in Dubai. 